\title{
Gastro-intestinal symptoms are associated with a lower in-hospital mortality rate in frail older patients hospitalized for COVID-19
}

\author{
N. Lanthier ${ }^{1,2,3}$, C. Mahiat ${ }^{3}$, S. Henrard ${ }^{4,5}$, P. Stärkel ${ }^{1,2,3}$, I. Gilard ${ }^{3}$, I. De Brauwer ${ }^{3,4}$, P. Cornette ${ }^{3,4}$, B. Boland ${ }^{3,4}$ \\ (1) Service d'Hépato-gastroentérologie, Cliniques universitaires Saint-Luc, UCLouvain, Brussels, Belgium ; (2) Laboratory of Gastroenterology and Hepatology, Institut de \\ Recherche Expérimentale et Clinique (IREC), UCLouvain, Brussels, Belgium; (3) Service de Gériatrie, Cliniques universitaires Saint-Luc, UCLouvain, Brussels, Belgium; \\ (4) Institute of Health and Society (IRSS), UCLouvain, Brussels, Belgium ; (5) Louvain Drug Research Institute (LDRI), Clinical Pharmacy research group, UCLouvain, \\ Brussels, Belgium.
}

Keywords : COVID-19, diarrhea, coronavirus, digestive symptoms, liver, mortality prognosis.

\section{To the Editor,}

In the previous issue of Acta Gastro-Enterologica Belgica, a meta-analysis on the presence of gastrointestinal (GI) symptoms in patients with COVID-19 was published
(1). The pooled prevalence of GI manifestations was $12 \%$ with diarrhea being the most frequent digestive symptom $(8 \%)$. Other reports show an incidence rate of diarrhea ranging from $2 \%$ to $50 \%$. A question emerges after reading this systematic review : is the presence of these GI symptoms associated with a particular prognosis?

At Cliniques universitaires Saint-Luc, we analyzed the first cohort of geriatric patients admitted for

Table 1. - Patients' characteristics according to in-hospital cure or death

\begin{tabular}{|c|c|c|c|c|}
\hline Variables & $\begin{array}{c}\text { Total }(\mathrm{n}=50) \\
\text { Median }\left(\mathrm{P}_{25} ; \mathrm{P}_{75}\right) \\
\text { or } \mathrm{n}(\%)\end{array}$ & $\begin{array}{c}\text { Alive }(\mathrm{n}=24) \\
\text { Median }\left(\mathrm{P}_{25} ; \mathrm{P}_{75}\right) \\
\text { or } \mathrm{n}(\%)\end{array}$ & $\begin{array}{c}\text { Dead }(\mathrm{n}=26) \\
\text { Median }\left(\mathrm{P}_{25} ; \mathrm{P}_{75}\right) \\
\text { or } \mathrm{n}(\%)\end{array}$ & p-value \\
\hline \multicolumn{5}{|l|}{ Demographics } \\
\hline Age, years & $88(83 ; 92)$ & $87(81 ; 89.5)$ & $90(87.25 ; 94)$ & 0.005 \\
\hline \multicolumn{5}{|l|}{ COVID-19 symptoms } \\
\hline Respiratory symptoms & $36(72.0)$ & $17(70.8)$ & $19(73.1)$ & 0.860 \\
\hline Febrile symptoms & $30(60.0)$ & $15(62.5)$ & $15(57.7)$ & 0.729 \\
\hline $\begin{array}{l}\text { Digestive symptoms } \\
\text { Diarrhea } \\
\text { Abdominal pain } \\
\text { Nausea/vomiting } \\
\text { Anorexia }\end{array}$ & $\begin{array}{c}15(30.0) \\
12(24.0) \\
3(6.0) \\
3(6.0) \\
5(10.0) \\
\end{array}$ & $\begin{array}{l}11(45.8) \\
9(37.5) \\
3(12.5) \\
1(4.2) \\
4(16.7) \\
\end{array}$ & $\begin{array}{l}4(15.4) \\
3(11.5) \\
0(0.0) \\
2(7.7) \\
1(3.8) \\
\end{array}$ & $\begin{array}{l}\mathbf{0 . 0 1 9} \\
\mathbf{0 . 0 3 2} \\
0.103 \\
0.999 \\
0.182 \\
\end{array}$ \\
\hline \multicolumn{5}{|l|}{ Laboratory tests } \\
\hline $\mathrm{CRP}, \mathrm{mg} / \mathrm{L}$ & $69.5(42.5 ; 98.5)$ & $53.5(42 ; 76.5)$ & $82(52.5 ; 145.5)$ & 0.072 \\
\hline LDH, IU/L & $308(278.5 ; 408.5)$ & $288(251 ; 310)$ & $380(306 ; 518.5)$ & 0.006 \\
\hline ASAT, IU/L & $33.5(25 ; 62)$ & $29(21.25 ; 36.75)$ & $38.5(32.5 ; 97.25)$ & 0.005 \\
\hline ALAT, IU/L & $21(15 ; 30)$ & $20(15.25 ; 27.75)$ & $29(13.5 ; 40.25)$ & 0.179 \\
\hline \multicolumn{5}{|l|}{ Lung imaging } \\
\hline Marked lung infiltrates & $20(40.0)$ & $5(20.8)$ & $15(57.7)$ & 0.008 \\
\hline
\end{tabular}

Abbreviations : CRP : C-reactive protein ; LDH : lactate dehydrogenase ; ASAT : aspartate-amino-transferase ; ALAT : alanine amino-transferase. Bold values indicate a statistically significant difference with a p-value less than 0.05 .

COVID-19 (2). The study population consisted of 50 consecutive patients admitted between March 11 and April 17, 2020 to the geriatric COVID-19 units of our Belgian academic hospital, with severe acute respiratory syndrome coronavirus 2 (SARS-CoV-2) infection confirmed by reverse-transcriptase-polymerase-chainreaction (RT-PCR) (2). Another inclusion criteria was the presence of vulnerability/frailty defined by a clinical frailty scale equal or higher than 4 (2). In this cohort, GI symptoms were present in $30 \%$ of the patients at the time of COVID-19 diagnosis. We then compared the patients on the basis of intra-hospital mortality (IHM), with a total IHM of $52 \%$, and assessed the factors associated with it (2). Interestingly, GI symptoms were significantly more frequent in the patients alive at discharge than in those who died in the hospital $(45.8 \%$ vs. $15.4 \%, \mathrm{p}=0.02)$

Correspondence to : Prof. Nicolas Lanthier, Service d'Hépato-gastroentérologie, Cliniques universitaires Saint-Luc, UCLouvain, Avenue Hippocrate, 10, 1200 Brussels, Belgium. Phone : 00.32.2.764.28.22. Fax : 00.32.2.764.53.46.

E-mail : Nicolas.Lanthier@uclouvain.be

Submission date : 09/12/2020

Acceptance date : $22 / 12 / 2020$ 
(2). IHM was significantly lower in the presence than in the absence of GI symptoms $(26.7 \%$ vs. $62.9 \%$, crude relative risk : $0.42, \mathrm{p}=0.03)$. Among GI symptoms, the presence of diarrhea was significantly higher among patients discharged alive compared to deceased patients (Table 1).

Of note, liver tests abnormalities, already suspected as a potential negative prognostic factor of poor outcome (3), were more common in non-survivors, with a significantly higher value of aspartate aminotransferase (ASAT), probably as a consequence of a more severe inflammatory condition (increased rate of marked lung infiltrates and higher C-reactive protein level) (Table 1).

So, surprisingly, the presence of diarrhea upon COVID-19 diagnosis was protective of IHM. In agreement with our observation, diarrhea as the initial symptom was also shown as a beneficial factor in other case series. In the first cohort of 18 patients diagnosed with SARS-CoV-2 infection reported in Singapore, diarrhea was only present in patients who did not require supplemental oxygen (4). In another retrospective cohort focusing on patients hospitalized at the Wuhan university Hospital during the "first wave", most patients in the non-surviving group were older and had significantly less diarrhea symptoms (3\%) compared to surviving patients (9\%) (5).

We know that viral shedding of SARS-CoV-2 in stool samples occurs in a substantial proportion of patients, and that fecal-oral transmission is plausible. Indeed, the angiotensin-converting enzyme 2 (ACE2) receptors of SARS-CoV-2 are mainly expressed in pulmonary and intestine epithelial cells. This led to precise recommendations for endoscopy units for example (6). Furthermore, the presence of GI symptoms has also important implications for the early identification of individual cases that would influence testing, isolation and treatment strategies.

According to these data, digestive symptoms at diagnosis in this geriatric population is related to a less fatal disease, while the intensity of liver test disturbance seems to correlate with the cytokine storm related to the severity of lung involvement. Further prospective studies, with standardized quantification of GI symptoms and a clear definition of diarrhea, are required to evaluate whether this manifestation is a predictive factor for COVID-19 prognosis.

\section{References}

1. MEROLA E, ARMELAO F, DE PRETIS G. Prevalence of gastrointestinal symptoms in coronavirus disease 2019 : a meta-analysis. Acta Gastroenterol. Belg., 2020, 83(4) : 603-15.

2. MAHIAT C, HENRARD S, GILARD I, LANTHIER N, STÄRKEL P, DE BRAUWER I, et al. COVID-19: présentation clinique et mortalité des 50 premiers patients gériatriques hospitalisés aux Cliniques universitaires SaintLuc au printemps 2020. Louv. Med., nov 2020, 139(09-10) : 503-11.

3. MEROLA E, PRAVADELLI C, DE PRETIS G. Prevalence of liver injury in patients with coronavirus disease 2019 (COVID-19) : A systematic review and meta-analysis. Acta Gastroenterol. Belg., 2020, 83(3) : 454-60.

4. YOUNG BE, ONG SWX, KALIMUDDIN S, LOW JG, TAN SY, LOH J, et al. Epidemiologic Features and Clinical Course of Patients Infected With SARSCoV-2 in Singapore. JAMA, 2020, 323(15) : 1488 .

5. WANG Z, YE D, WANG M, ZHAO M, LI D, YE J, et al. Clinical Features of COVID-19 Patients with Different Outcomes in Wuhan : A Retrospective Observational Study. Biomed. Res. Int., 2020, 1-10.

6. SINONQUEL P, AERTS M, BADAOUI A, BISSCHOPS R, BLERO D, DEMEDTS I, et al. Bsgie survey on covid-19 and gastrointestinal endoscopy in belgium : Results and recommendations. Acta Gastroenterol. Belg., 2020, 83(2) : 344-54. 